\title{
Secondary Central Nervous System Hodgkin Lymphoma
}

National Cancer Institute

\section{Source}

National Cancer Institute. Secondary Central Nervous System Hodgkin Lymphoma. NCI

Thesaurus. Code C114949.

A Hodgkin lymphoma that has metastasized to the central nervous system following the initial presentation in another nodal or extranodal site. 